\title{
AN ASSAY FOR THE ANTITHROMBOTIC ACTIVITY OF ANTICOAGULANTS
}

\author{
BY \\ O. R. BLAKE, J. G. ASHWIN, AND L. B. JAQUES \\ From the Department of Physiology and Pharmacology, University of Saskatchewan, \\ Saskatoon, Saskatchewan, Canada
}

(RECEIVED FOR PUBLICATION APRIL 30, 1958)

\begin{abstract}
Anticoagulants have been used for 20 years for the treatment of thrombosis. This practice has been based on the original experiments of Pupini (1932), Murray, Jaques, Perrett, and Best (1937), and Dale and Jaques (1942) which showed that anticoagulants could prevent the formation of experimental thrombi in dogs. There has been, however, no method reported by which it is possible to produce thrombosis in small animals for rapid assessment of the incidence of the lesion with different treatments. Such a method would be of value both to assess the relative activity of different anticoagulants in preventing thrombosis and also to make possible the quantitative experimental study of factors affecting thrombus formation in vivo. The present study was undertaken with this purpose and describes a simple method which appears to attain these objectives.
\end{abstract}

\section{Method}

Albino rats of both sexes, weighing between 150 and $300 \mathrm{~g}$., were employed. The animals were anaesthetized with ether and immobilized on their backs. The neck was clipped, and a skin incision made from the middle of the right clavicle for $1 \mathrm{~cm}$. anteriorly. The subcutaneous tissues were freed with forceps to expose a section of the jugular vein $1 \mathrm{~cm}$. long. Haemorrhage was controlled by light pressure with moistened absorbent cotton. Four to six drops $(0.2 \mathrm{ml}$.) of $10 \% \mathrm{v} / \mathrm{v}$ formalin in $60 \%$ methyl alcohol were now applied to the adventitia of the vessel by means of a dropper, and the skin incision closed by clips or suture. After 24 hours the vessel was examined to determine vascular occlusion. In developing the method, a number of experiments were done in which the vessel was left $\mathbf{4 8}$ hours before inspection.

After the incision was reopened, the vessel was inspected carefully and the presence of a clot recorded. Finally the vessel was opened with scissors and the clot checked visually. In the case of thrombosis the vessel is dark and discoloured. Absence of flow on cutting was not used as a final criterion, since this could be due to constriction and flow sometimes persisted in the presence of a large clot incompletely obstructing the lumen.

"Depo" heparin was kindly supplied by the Upjohn Co., Kalamazoo, Michigan, in $1 \mathrm{ml}$. vials containing $20 \mathrm{mg}$. of heparin sodium, $180 \mathrm{mg}$. of gelatin, and $80 \mathrm{mg}$. of anhydrous dextrose preserved with sodium ethyl mercurithiosalicylate $1: 10,000$. We are indebted to Hoffman-LeRoche Inc., Nutley, New Jersey, for "treburon." This was received as a sterile solution in $2 \mathrm{ml}$. ampoules. It was an experimental preparation and $1 \mathrm{ml}$. contained $250 \mathrm{mg}$. of RO 2-3053. These ampoules were not preserved with phenol. Both of these drugs were injected subcutaneously five hours after the operation. The injection was repeated every eight hours. Doses are reported in $\mathrm{mg}$./100 g. body weight given as a single injection.

"Dicoumarol" was kindly supplied by Chas. E. Frosst and Co., Montreal. This was incorporated in fox chow and fed at a level of 10 to $100 \mathrm{mg}$. $/ \mathrm{kg}$. per day for three days. "Warfarin," supplied by S. B. Penick \& Co., New York, was similarly dispensed for doses of 0.03 to $2 \mathrm{mg}$. $/ \mathrm{kg}$. The animal cages were inspected daily to ensure that all of the food was eaten. Blood was taken for prothrombin times from the tail vein, and the prothrombin times were determined by the method of Schwager and Jaques (1949), adding 2 drops of blood to 2 drops of rabbit brain thromboplastin suspension.

\section{Results}

Apitz (1938) observed that the application of alcohol to the outer wall of the jugular vein of rabbits produced a thrombus. In preliminary experiments absolute alcohol and $10 \%$ formalin were applied to the adventitia of the jugular veins of rats. Both produced an occlusion in most of the vessels treated. The vessels found occluded at 24 hours showed a typical platelet thrombus on histological study. The method was standardized using $10 \%$ formalin in $60 \%$ methyl alcohol. The incidence of thrombosis is shown in Table $I$. Results are shown for three separate investigators 
TABLE I

INCIDENCE OF THROMBOSIS IN NORMAL RATS PRODUCED WITH $10 \%$ FORMALIN SOLUTION

\begin{tabular}{|c|c|c|c|c|}
\hline Series & Operator & $\begin{array}{l}\text { No. of } \\
\text { Rats }\end{array}$ & $\begin{array}{l}\text { No. with } \\
\text { Thrombus }\end{array}$ & $\begin{array}{l}\% \text { Incidence } \\
\text { of } \\
\text { Thrombosis }\end{array}$ \\
\hline $1 *$ & OB & 20 & 16 & 80 \\
\hline $\begin{array}{r}2 \\
3 \\
4 \\
5 \\
6 \\
7 \\
8 \\
9 \\
10 \\
11\end{array}$ & $\begin{array}{c}\text { OB } \\
\text { OB } \\
\text { OB } \\
\text { JA } \\
\text { JA } \\
\text { JA } \\
\text { JA } \\
\text { JA } \\
\text { ER } \\
\text { ER }\end{array}$ & $\begin{array}{r}30 \\
10 \\
10 \\
18 \\
9 \\
20 \\
19 \\
21 \\
10 \\
9\end{array}$ & $\begin{array}{r}22 \\
6 \\
7 \\
9 \\
7 \\
12 \\
10 \\
11 \\
7 \\
7\end{array}$ & $\begin{array}{l}73 \\
760 \\
70 \\
50 \\
78 \\
60 \\
59 \\
53 \\
70 \\
78\end{array}$ \\
\hline Total & & 176 & 114 & \\
\hline
\end{tabular}

Overall incidence $=$

$64 \cdot 8 \%$

Mean incidence for 10 experiments examined at 24 hours $=65 \cdot 1 \%$ S.D. $\pm 9 \cdot 7$.

* Veins examined 24 hours after operation except in series 1 , in which rats were examined after 48 hours.

and the experiments were spread over a period of five years. The overall incidence was $64.8 \%$. There was a slightly higher incidence when the inspection was made 48 hours after the application of the agent. There appeared to be no significant difference in the incidence of thrombosis in rats between sexes, sources of rats, or operators.

Simply stripping the vein without the addition of formaldehyde has resulted in a high incidence of thrombosis, but this varied with the operator. More consistent results were obtained with formaldehyde solution. Moreover, in a series not treated with formaldehyde, there was a very low incidence of thrombosis 48 hours later. This suggested that the thrombus had been dislodged. The evident inflammatory reaction and even necrosis observed microscopically in the formaldehyde-treated series served to fix the thrombus in situ and prevent this. Observations at a quarter, half, one, and six hours indicated that the occlusion of the vessel was due to the slow formation of a platelet thrombus and not to the immediate formation of an intravascular clot. In several series, portions of vein were removed, and, after routine fixation and section, examined microscopically. As indicated above, blood might flow in the presence of a thrombus, and due to vasoconstriction fail to flow in its absence, but visual inspection of the clot microscopically checked with the microscopic results. In all cases, the occlusion proved to be in part or whole a true platelet thrombus. Macroscopically, it contained a distinct pink body quite easily distinguished from the dark, almost black, intravascular blood clot. Microscopically, with haematoxylin and eosin, the occluding mass appeared pinkish with the typical pattern of a platelet thrombus and showing occasional darker masses of red cells.

Comparison of Depo Heparin and Treburon in Rats.-Groups of rats were subjected to the operation and then injected with "depo heparin" or "treburon" subcutaneously five hours later. The injections were repeated every eight hours. The results are shown in Table II. The results indicate that as the dose of "depo heparin " or of "treburon" increases, the incidence of thrombosis decreases. There were many deaths with the larger doses of anticoagulants, particularly if the rats were not examined until 48 hours after the operation. This brought about a drastic reduction in the number of animals available for

TABLE II

INCIDENCE OF THROMBOSIS AFTER SUBCUTANEOUS ADMINISTRATION OF DEPO-HEPARIN AND TREBURON FIVE HOURS AFTER OPERATION

\begin{tabular}{c|c|c|c|c}
\hline & \multicolumn{2}{|c|}{ Depo-Heparin } & \multicolumn{2}{|c}{ Treburon } \\
\cline { 2 - 4 } $\begin{array}{c}\text { Dose } \\
\text { (mg./100 g.) }\end{array}$ & $\begin{array}{c}\text { No. of } \\
\text { Rats }\end{array}$ & $\begin{array}{c}\text { Incidence } \\
\text { of } \\
\text { Thrombosis } \\
(\%)\end{array}$ & $\begin{array}{c}\text { No. of } \\
\text { Rats }\end{array}$ & $\begin{array}{c}\text { Incidence } \\
\text { of } \\
\text { Thrombosis } \\
(\%)\end{array}$ \\
\hline 1 & 10 & 80 & 10 & 90 \\
2 & 8 & 87 & 8 & 75 \\
3 & 10 & 60 & 16 & 47 \\
4 & 10 & $\frac{67}{\%}$ & 10 & 80 \\
10 & 9 & 38 & 24 & 54 \\
20 & 13 & 42 & 18 & 44 \\
40 & 10 & 40 & - & - \\
\hline
\end{tabular}

Veins examined afier 24 hours except with $1,2,3 \mathrm{mg} / 100 \mathrm{~g}$. dose (examined after 48 hours).

examination at the higher dose levels. The haemorrhage was generally at the site of operation, but some animals showed haemorrhage at the site of injection. The relative effectiveness of "depo heparin" and "treburon" was about the same. Both drugs reduced the incidence of thrombosis to $40 \%$. The incidence of thrombosis was converted to probits and the relative antithrombotic activity from the regression line was $0.81: 1.00$ for "treburon": "depo heparin."

Incidence of Experimental Thrombosis after Dicoumarol and Warfarin.-Male rats were given indirect anticoagulants in varying amounts by incorporating the compounds in their diet for three days. On the third day the rats were anaesthetized lightly with ether, a tail vein puncture was made to obtain blood for prothrombin times, and the right jugular vein was exposed and treated with the formalin solution. Twenty-four hours later the rats were again anaesthetized with ether and the jugular vein was examined for thrombosis. The prothrombin 
time was determined from blood taken from one of the jugular veins. The incidence of thrombosis was determined by careful examination of the vein, judging if it contained a clot both by appearance and by estimation of internal patency and blood flow.

The post-operative prothrombin times were often found to vary considerably above and below those of the first day, and since this change could not be foretold or controlled the two times were averaged. The normal prothrombin time by the method used is about $26 \mathrm{sec}$. The results are shown in Fig. 1, as is the incidence for various prothrombin times. As observed in this laboratory in other work, when dicoumarol is given to rats, there is a wide distribution of resulting prothrombin times at most dose levels. Warfarin is much more effective than dicoumarol in the rat, requiring only $1 / 300$ by weight. Further, the response appears to be somewhat more uniform, although even with the highest dosage used one rat out of 10 gave a normal prothrombin time. This appears to be the

\section{DICUMAROL}

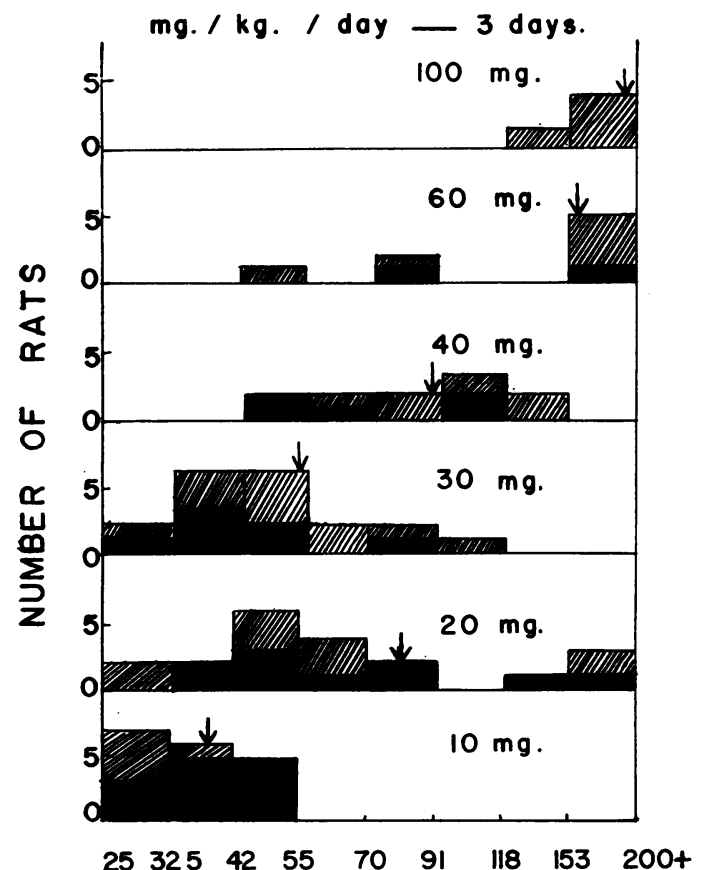

problem of individual resistance to prothrombopenic drugs, described by Link (1943-44) with dicoumarol in rabbits.

When the percentage incidence of thrombosis was plotted against the dose of anticoagulant (Fig. 2a) there was a marked reduction in the incidence with "warfarin" and less reduction with dicoumarol. There appeared to be little correlation between dose and incidence of thrombosis. As there is poor correlation between the dose of dicoumarol and resulting mean prothrombin time (Fig. 1), the data were replotted. The rats were placed in groups according to the individual mean prothrombin time, irrespective of the amount of anticoagulant received. Any groups with fewer than 10 rats were not used. The incidence of thrombosis for these groups is shown in Fig. 2b. It can be seen that the incidence of thrombosis decreases stepwise with the increase in prothrombin time. Separate calculations for "warfarin" and dicoumarol indicate a similar relationship between their resulting prothrombin time and the incidence of

\section{WARFARIN}

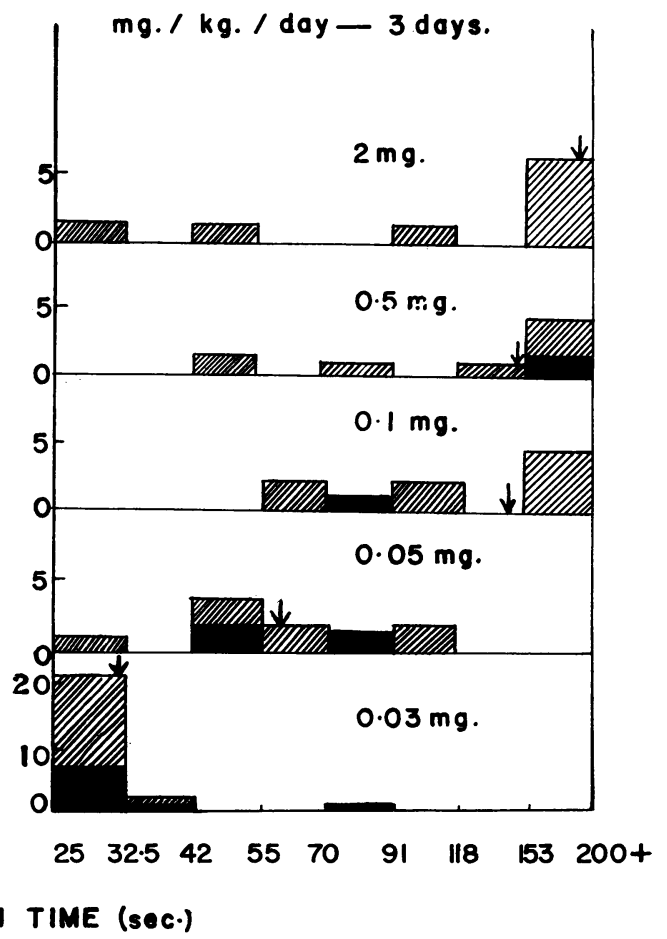

Fig. 1.-Effect of dicoumarol and "warfarin" on the prothrombin times of operated rats. Prothrombin time intervals, $\Delta$ $T=T_{2}-T_{1}=0.3 \times T_{1}$; with $T_{0}=25 \mathrm{sec}$. $\mathscr{W}=$ Number of cases with prothrombin times in range shown. $\quad=$ Number of cases with thrombosed vein. $\downarrow=$ Mean prothrombin time for any given dose of anticoagulant. 


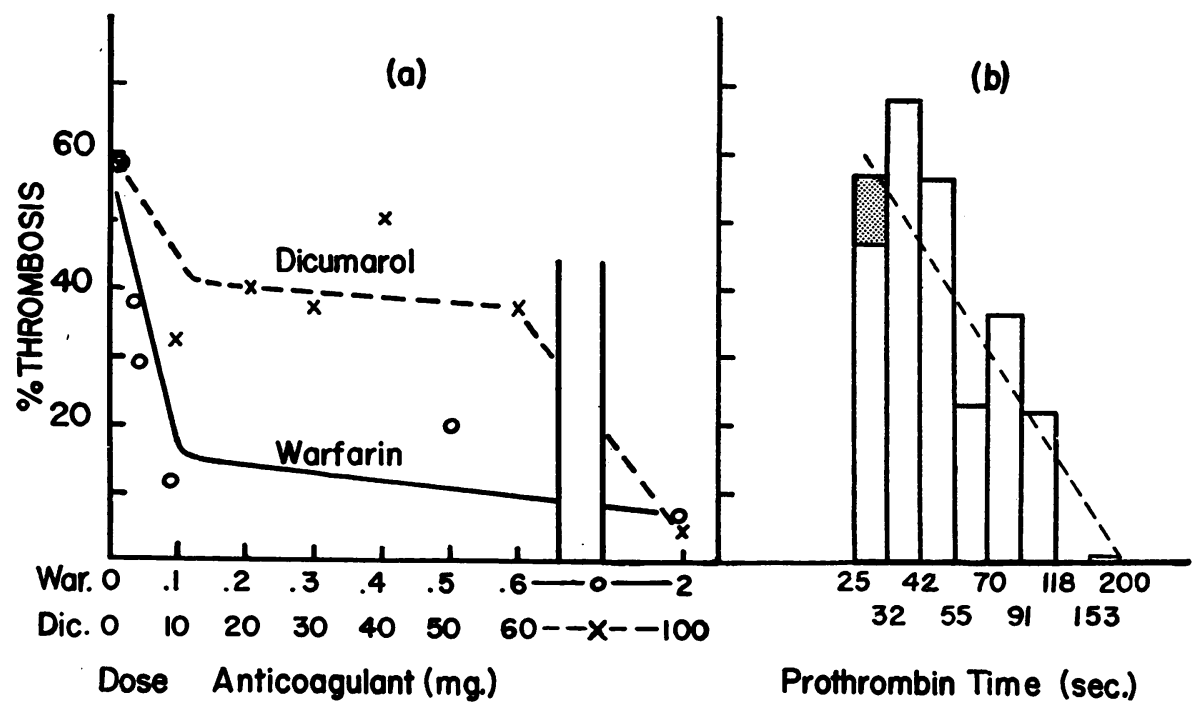

FIG. 2.-(a) Incidence of thrombosis in rats related to the dose of indirect anticoagulants. (b) Incidence of thrombosis in rats related to the prothrombin time following indirect anicoagulants. 3 : Incidence without anticoagulant treatment.

thrombosis, but the numbers participating in some groups were not sufficient for analysis.

\section{Discussion}

Many methods have been used to produce thrombosis and intravascular clotting or intravascular clotting alone in larger experimental animals. Starting with Wooldridge in 1886 , many have injected thromboplastin (tissue extracts) into dogs for this purpose (Wooldridge, 1893). Tubes of glass and collodion have been placed in the circulation, sclerosing agents, catgut, and clots have been introduced, trauma of the vessel wall, tying of the vessel, occlusion by pressure, and the application of an electrical charge have all been used. The present method appears to be the first using the rat. It has the advantage that it can be quickly and easily performed so that experiments may be designed to test the effect of various factors on the incidence of thrombosis with a measure of statistical significance. The incidence of thrombosis produced by this technique was not affected by the age or sex of the rats. It is believed that the principle used, local damage, is similar to that which frequently results in clinical thrombosis. The inflammation and necrosis of the vessel wall due to the formalin are probably contributory factors to the fixation of the thrombus. McGovern (1955) has shown that a probably adequate stimulus for thrombosis is the tissue anoxia which arises from a mere "stripping" of the vessels concerned, but we found a variable incidence when stripping alone was employed.

A thrombus can be detected in a few rats half an hour after operation, and the incidence increases thereafter. The failure of depot heparin and "treburon" to prevent completely the thrombus formation is probably due to the anticoagulants being given five hours after operation. Lately it has been shown that when heparin is given intravenously immediately after the operation, extremely small doses will completely prevent thrombosis without haemorrhage. In the series with depot heparin and "treburon," it appeared that "depot heparin" had a greater haemorrhagic activity than "treburon" $(1.0: 0.6)$ in line with its greater anticoagulant activity. Since most of the animals showed a large haematoma in the neck, it was assumed that the operation was responsible, but in a control series with anticoagulant alone it was found that the incidence of haemorrhage was just as high. The high incidence of haemorrhage in rats receiving $5 \mathrm{mg}$. $/ 100 \mathrm{~g}$. "depo-heparin" was not observed by Haist (1938) with plain heparin and is in marked contrast to the general observation with other species of experimental animals, in which the blood can be rendered incoagulable with heparin without any signs of haemorrhage.

The variation in prothrombin time following administration of equal amounts of dicoumarol or of "warfarin" in the rat's food was not due to 
variations in absorption. As intraperitoneal injection of "warfarin" resulted in variations in the prothrombin time similar to that following oral administration, the differences in utilization of the drug are chiefly responsible.

The fact that a relationship has been established between the prothrombin time value and the incidence of thrombosis is a significant observation. Since the initial paper of Murray et al. (1937) on the application of anticoagulants to the prevention of thrombosis, it has been universally assumed that there is some correlation between the degree of impaired coagulation and the reduced incidence of thrombosis following the use of anticoagulants. It has been, however, extremely difficult to obtain any evidence for this, either in experimental animals or in man, and the data presented for dicoumarol and "warfarin" are most important, showing, in rats, that, while there is no correlation between the drug dosage and reduction in incidence of thrombosis, there is a correlation between the prothrombin time produced by indirect anticoagulants and the reduced incidence of thrombosis.

What is the therapeutic level for the anticoagulants? At present there is no evidence that there is a therapeutic level at which intravascular clotting can be absolutely prevented. Several investigators reported a lowering of the incidence of experimentally produced thrombosis in anticoagulant-treated animals compared with a control series. The results obtained demonstrate that the degree of reduction in incidence of thrombosis is dependent on the degree of reduction in blood coagulability for the indirect anticoagulants. The latter is affected by the nutritional status, genetic constitution, and pre-existing hypercoagulability or hypocoagulability and hence these factors determine the dosage of drug required. Just as there is a range of prothrombin times in which the incidence of thrombosis is reduced proportional to the prothrombin time, so presumably there are varying degrees of thrombotic tendency which will require a greater degree of hypocoagulability to prevent thrombosis. If one could estimate quantitatively the degree of thrombotic tendency in different clinical conditions (post-operative, etc.), and relate this to the animal, then obviously it should be possible to predict the degree of protection required for these. However, the method described should in any case be valuable in comparing the relative antithrombotic activity of different anticoagulants.

\section{Summary}

A method is described for producing thrombosis in rats by the application of formalin to the jugular vein and inspecting the vein after 24 hours. The percentage incidence of thrombosis was $65.1 \pm 9.7$ for $200 \mathrm{~g}$. rats.

The administration of "depo heparin" and "treburon" subcutaneously reduced this incidence of thrombosis to $40 \%$. The ratio of antithrombotic activity thus determined for "treburon": "depo-heparin" was $0.8: 1.0$.

In the rats used, the prothrombopenic activity of "warfarin" given orally to rats over three days was about 300 times that of dicoumarol on a weight basis, as judged by the increased prothrombin time. Dicoumarol and "warfarin" reduced the incidence of thrombosis. There was little correlation between the dose of drug and incidence of thrombosis, but there was a significant correlation between the incidence of thrombosis in rats and the prothrombin time levels produced by these drugs.

We wish to acknowledge the valuable assistance of Dr. E. F. Routley, who participated in a part of the programme, and the kind encouragement and advice of Professor D. F. Moore and Dr. J. E. Newell, of the Department of Pathology, University of Saskatchewan. This work was supported with a grant from the Defence Research Board of Canada.

\section{REFERENCES}

Apitz, K. (1938). Kolloid Z., 85, 196.

Dale, D. U., and Jaques, L. B. (1942). Canad. med. Ass. J., 46, 546. Haist, R. (1938). In Jaques, L. B., Charles, A. F., and Best, C. H. (1938). Acta med. scand., Suppl., 90, p. 190.

Link, K. P. (1943-44). Harvey Lect., 39, 162.

Link, K. P. (1943-44). Harvey Lect., 39, 162. 283.

Murray, D. W. G., Jaques, L. B., Perrett, T. S., and Best, C. H. (1937). Surgery, 2, 163.

Pupini, G. (1932). Arch. ital. Chir., 32, 661.

Schwager, P. G., and Jaques, L. B. (1949). Canad. med. Ass. J., 60, 258 .

Wooldridge, L. C. (1893). On the Chemistry of the Blood. Kegan Paul, Trench, Trübner and Co., London. 